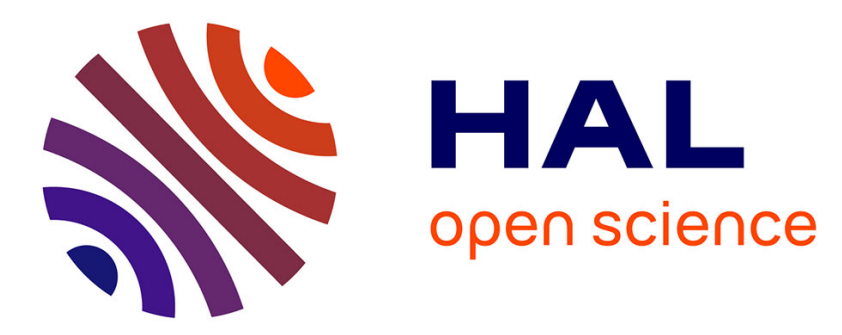

\title{
Long-term effectiveness and side effects of mandibular advancement devices on dental and skeletal parameters
}

\author{
G.Vigié Du Cayla, J.M. Collet, V. Attali, J.B. Kerbrat, L. Benslama, P.
}

Goudot

\section{- To cite this version:}

G.Vigié Du Cayla, J.M. Collet, V. Attali, J.B. Kerbrat, L. Benslama, et al.. Long-term effectiveness and side effects of mandibular advancement devices on dental and skeletal parameters. Journal of Stomatology, Oral and Maxillofacial Surgery, 2019, 120 (1), pp.7-10. 10.1016/j.jormas.2018.09.005 . hal-02172367

\section{HAL Id: hal-02172367 \\ https://hal.sorbonne-universite.fr/hal-02172367}

Submitted on 3 Jul 2019

HAL is a multi-disciplinary open access archive for the deposit and dissemination of scientific research documents, whether they are published or not. The documents may come from teaching and research institutions in France or abroad, or from public or private research centers.
L'archive ouverte pluridisciplinaire HAL, est destinée au dépôt et à la diffusion de documents scientifiques de niveau recherche, publiés ou non, émanant des établissements d'enseignement et de recherche français ou étrangers, des laboratoires publics ou privés. 


\title{
Long-term effectiveness and side effects of mandibular advancement devices on dental and skeletal parameters
}

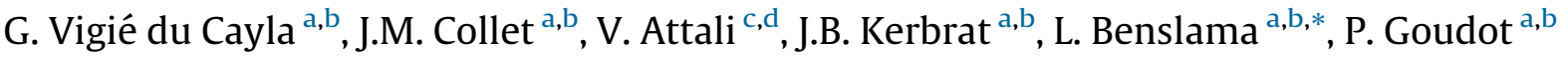 \\ a Service de stomatologie et chirurgie maxillo-faciale, AP-HP, DHU FAST, GH Pitié - Salpêtrière - Charles-Foix, 75013, Paris, France \\ borbonne Universités, UPMC université Paris 06, UMR 8256 B2A, 75005, Paris, France \\ 'Sorbonne Université, INSERM, UMRS1158 Neurophysiologie Respiratoire Expérimentale et Clinique, Paris, France \\ d Service des pathologies du Sommeil (Département "R3S"), AP-HP, Groupe Hospitalier Pitié-Salpêtrière Charles-Foix, 75013 Paris, France
}

Keywords:

Obstructive sleep apnea

Mandibular advancement

Side effects

\begin{abstract}
A B S T R A C T
Introduction: Continuous positive airways pressure, generally used to treat obstructive sleep apneahypopnea syndrome (OSAHS), is not tolerated well by many patients. An alternative is to treat OSAHS with mandibular advancement devices (MAD). This research assesses the long term ( $>2$ years) effectiveness and the side effects on dental and skeletal parameters of these devices.

Material and methods: We selected 24 patients with moderate to severe OSAHS. All were treated with MADs for at least 2 years. We gathered cephalometric teleradiographs in centric relation and sleep recordings before and after the patients were treated. We evaluated the patients' apnea-hypopnea indexes (AHI) as well as their Epworth sleepiness scale (ESS) scores. We measured the inclination of the central incisors and the positions of the upper and lower jaws.

Results: Mandibular advancement devices were used for more than 2 years ( $3.9 \pm 1.9$ years). We observed a statistically significant decrease of the patients' AHI and their ESS scores. We also observed a modification of the inclination of the lower central incisors $(+0.521 ; P=0.047)$ and of the position of the maxilla $(-0.287 ; P=0.039)$.

Discussion: We demonstrated the clinical effectiveness of mandibular advancement devices for treating OSAHS, with a very low rate of side effects on dental and skeletal positions.
\end{abstract}

\section{Introduction}

Obstructive sleep apnea-hypopnea syndrome (OSAHS) is characterized by the occurrence of abnormally frequent episodes of partial (hypopnea) or complete obstruction (apnea) of the upper airway during sleep. This syndrome affects 2 to $4 \%$ of middle-aged male patients, 30 to $60 \%$ of male patients over 60 and 1 to $2 \%$ of female patients. The severity of the OSAHS is measured with the apnea-hypopnea index (AHI), i.e. the number of obstructive sleep apnea-hypopnea events per hour. The AHI is considered low when ranging between 5 and 15, moderate between 15 and 30, and severe above 30. Similarly, Epworth sleepiness scale (ESS) scores may be low, moderate, or severe.

The main treatment for adults suffering from severe or low to moderate OSAHS with severe daytime sleepiness is the continuous positive airway pressure (CPAP) machine. But many patients refuse to use it or do not tolerate it well, so an alternative treatment, the

\footnotetext{
* Corresponding author at: Service de stomatologie et chirurgie maxillo-faciale, AP-HP, DHU FAST, GH Pitié - Salpêtrière - Charles Foix, 75013, Paris, France.

E-mail address: lotfibenslama@gmail.com (L. Benslama).
}

mandibular advancement device (MAD), was designed. MADs are used as lifelong treatments to prevent the recurrence of OSAHS symptoms. Our goal is to demonstrate the effectiveness of MADs and to evaluate their side effects on teeth and jawbones.

\section{Material and methods}

To conduct our research, we selected 24 patients (15 men and 9 women) between 23 and 73 years of age (with an average of 54), and followed them between November 2009 and February 2016. All these patients had AHIs $\geq 15$ (confirmed by polysomnographic examinations) associated or not to daytime sleepiness. They had all begun their a MAD treatment. Each patient file was documented with 2 lateral cephalometric radiographs and 2 sleep recordings, made more than 2 years apart.

We used the AHI index, the number of obstructive apnea and hypopnea events per hour, the ESS, the inclination of the maxillary and mandibular central incisors, and the sagittal position of jawbones as evaluation criteria. The patients were treated with Somnodent $\AA$ or ORM ${ }^{\circledR}$ MADs. 
Each patient's sleep recording contains his/her age, gender, height, body mass index (BMI) as well as AHI, number of obstructive apnea and hypopnea events per hour, and ESS score. The X-ray follow-up includes a panoramic radiograph and a lateral cephalometric radiograph. Cephalometric analyses were performed: Delaire [1] and Ricketts [2] with Orthokis ${ }^{\circledR}$ (2016-22.01.c, Arakis).

The different points and lines we used are detailed on Figs. 1 and 2 . The cephalometric analysis yielded the following data:

- degree of pro/retromaxillism (distance F1 theoretical-F1 maxillary on the occlusal plane) and convexity (distance between ANasion-Pogonion);

- degree of pro/retromandibulism (distance theoretical F1-mandibular F1 on the occlusal plane) and facial angle (NasionPogonion-Francfort);

- maxillary central incisors inclination (distance from incisal edge to $\mathrm{d} 1$ on occlusal plane and $\mathrm{I} / \mathrm{F}$ angle) and mandibular central incisors inclination (distance from incisal edge to $\mathrm{d} 1$ on the occlusal plane and the angle i/A-Pogonion).

All these analyses were performed by the same practitioner.

As MAD treatments progressed, we met with the patients every 2 weeks to perform a gradual titration of mandibular advancement so as to obtain the best benefit-risk ratio. That was determined for each patient taking account of:

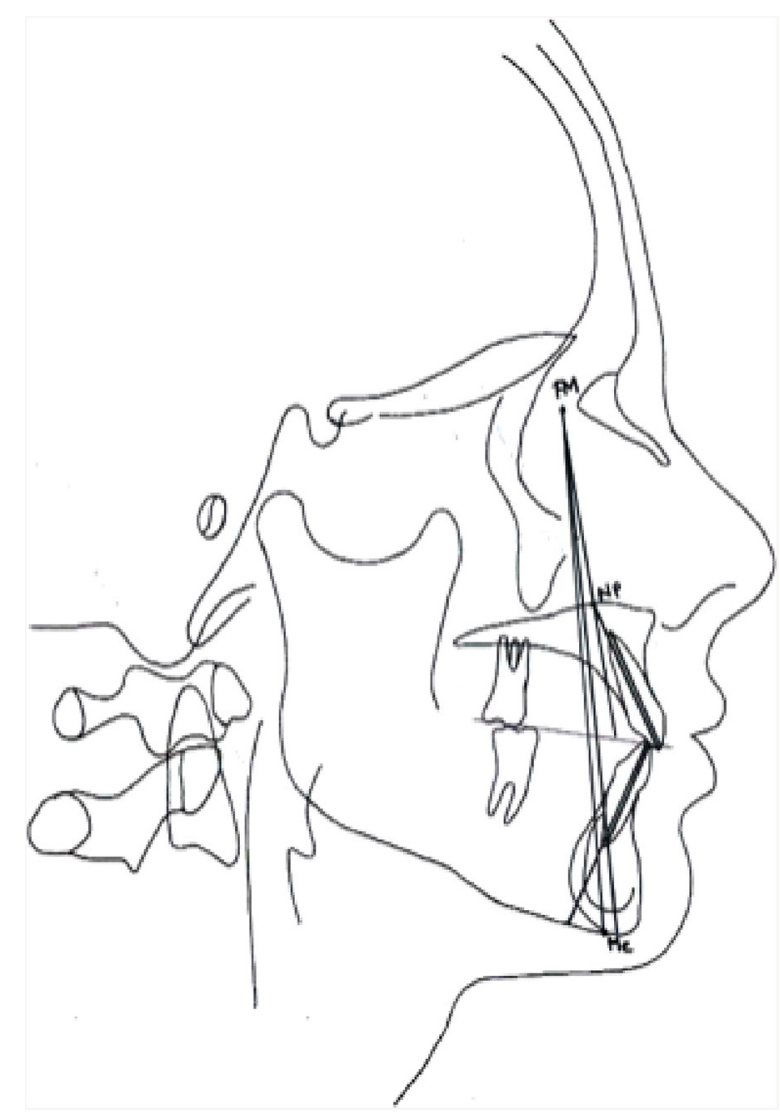

Fig. 1. Cephalometric variables of Ricketts' analysis used for this study: referent points: Porison (Po), suborbital point (Or), nation (Na), Pogonion (Pog), point A (A); referent lines and planes: Francfort Plane Porion-Orbital (Po-Or), facial plane Nasion-Pogonion (Na-Pog), dental line A-Pogonion (A-Pog); sagittal measurements: maxillary central incisor tilt [central mandibular incisor axis-A-Pogonion] (i-A-Pog angle), maxilla position [A-Nasion-Pogonion] (A-Na-Pog angle), mandibular position [Nasion-Pogonion-Francfort plane] (Na-Pog-F angle).

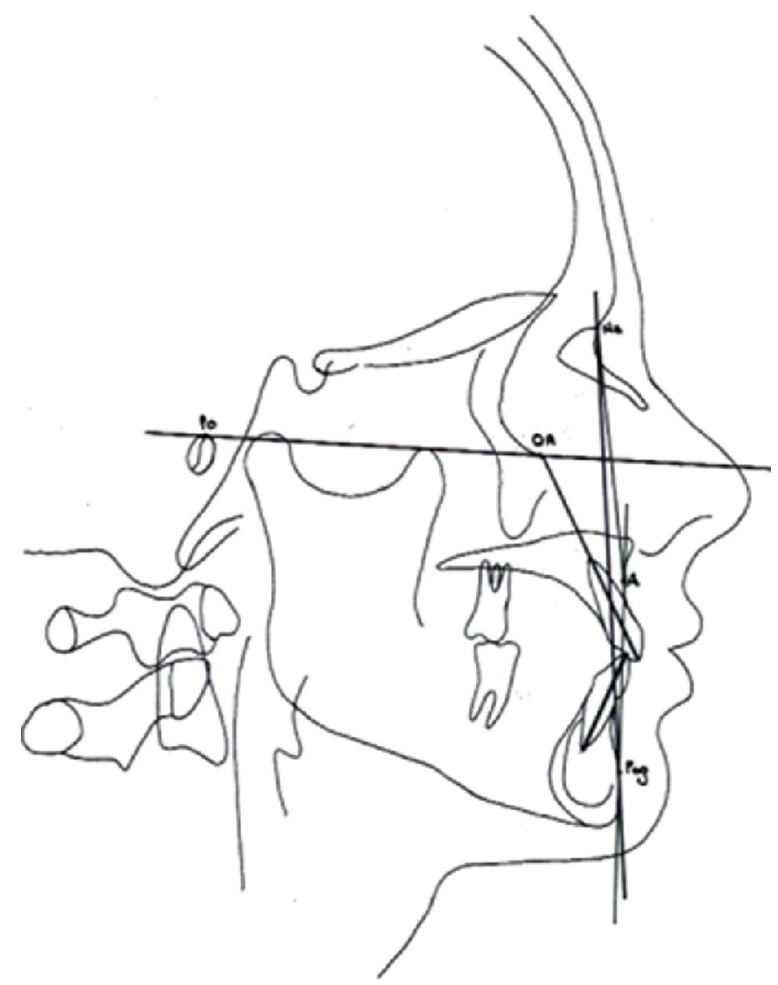

Fig. 2. Cephalometric variables of Delaire's analysis used for this study: P reference points: fronto-maxilla point (FM), naso-palatal point (Np), chin point (Me); reference lines and planes: maxillary central incisor axis (I), dental line d1, mandibular central incisor axis $i$, dental line $d 2$, orthognatic maxilla line (F1M), orthognatic mandibular line $(\mathrm{F} 1 \mathrm{~m})$; sagittal measurements: maxillary central incisor inclination D1 (distance incisal edge-d1 line on the occlusal plane in $\mathrm{mm}$ ), mandibular central incisor inclination D2 (distance incisal edge-d2 line on the occlusal plane in $\mathrm{mm}$ ), maxilla position D3 (distance between F1M and F1 reference line on the occlusal plan in mm), mandibular position D4 (distance between F1m line and F1 reference line on the occlusal plan in $\mathrm{mm}$ ).

his symptoms (decrease of snores, absence of compromising side effects in particular pain or discomfort);

- his polygraphics parameters (significant reduction in apneahypopnea episodes with a decrease of AHI by at least $50 \%$, increase of blood oxygen saturation level, increase in diastolic blood pressure);

- and his quality of life (reduction of daytime sleepiness with a significant decrease of Epworth's index, subjective and objective patient tolerance and compliance).

We also performed polysomnographic tests 3 months after the beginning of the treatment. Once the results were deemed satisfactory, we only saw the patients every 6 months.

After more than 24 months of wearing device (24 to 68 months), we realized a new X-rays check up: a lateral cephalometric radiograph and a panoramic radiograph under the same conditions as before treatment and we performed the cephalometric analysis of Delaire [1] and Ricketts [2] with the same software Orthokis ${ }^{\circledR}$ (2016-22.01.c, Arakis) to evaluate the impact of the mandibular advancement appliance on dentofacial structures. We also did a new polysomnographic control in order to compare the different parameters measured at baseline.

We defined 2 time references, T1 and T2, to study variations in dental and skeletal parameters. T1 corresponds to the cephalometric measurements of the lateral cephalometric radiographs taken before treatment and $\mathrm{T} 2$ to the cephalometric measurements on the lateral cephalometric radiographs taken after at least 2 years of treatment. This allowed us to assess the yearly migration 
Table 1

Statistical description of quantitative variables before treatment.

\begin{tabular}{lll}
\hline Before treatment & Average & Standard deviation \\
\hline Age (years) & 54.3 & 12.6 \\
BMI (kg/m ${ }^{2)}$ & 27.2 & 5.7 \\
AHI (number of AH events per hour) & 35.5 & 18.2 \\
ESS & 12.4 & 4.6 \\
Duration of follow-up (years) & 3.9 & 2.4 \\
\hline
\end{tabular}

of central incisors and jawbones between $\mathrm{T} 1$ and $\mathrm{T} 2$. If the average variation between measurements at $\mathrm{T} 1$ and $\mathrm{T} 2$ was positive (+), it indicated that there had been an increase. If the average variation was negative $(-)$, it indicated that there had been a decrease. The threshold for significance was set at $P<0.05$.

We defined 2 new time references to evaluate MAD effectiveness, T3 and T4, this time associated with the AHI and ESS values as well as with the number of obstructive apnea and hypopnea events per hour before and after treatment.

We used a average mandibular advancement of $6.8 \mathrm{~m}$ (range: 5 to $9 \mathrm{~mm}$ ). We then distributed the patients according to $\mathrm{AHI}$ and ESS values after treatment (T4).

The statistical analysis included descriptive and inferential statistics, and was made with the Shapiro-Wilk's, Student's T, and Mann-Whitney-Wilcoxon's tests. We used the software R (version 3.1.0, 2014, R Core Team).

\section{Results}

Out of the 24 patients selected for the study, 15 were men and 9 were women. The average age was $54.3 \pm 12.6$ years. The average body mass index (BMI) was $27.2 \pm 5.7 \mathrm{~kg} / \mathrm{m}^{2}$ and $79 \%$ suffered from obesity (BMI $\left.>30 \mathrm{~kg} / \mathrm{m}^{2}\right)$. The average AHI before treatment was $35.5 \pm 18.2$ per hour and the average ESS score was $12.4 \pm 4.6$. 13 patients suffered from moderate OSAHS; 11 from severe OSAHS. The average duration of the follow-up was $3.9 \pm 1.9$ years (Tables 1 ).

The statistical descriptions of cephalometric variables at T1 and T2, of AHI and ESS values and the number of obstructive apnea and hypopnea at $\mathrm{T} 3$ and $\mathrm{T} 4$ and of patient distribution depending on the values of AHI and ESS values after treatment are respectively presented in Tables 2, 3 and 4.

\section{Discussion}

We demonstrated that MADs were a valid therapeutic alternative for patients with OSAHS. Indeed, the polysomnographic recordings showed a significant decrease of their AHIs ( -26.15 ; $P=0.0001)$ and of the number of obstructive apnea events per hour $(-95 ; P=0.01)$, as noted in previous studies [16.41]. At the
Table 3

Stastical description of AHI and SSE values and the number of obstructive apnea hypopnea at T3 and T4 and of the mean difference of these values between T3 and T4.

\begin{tabular}{lll}
\hline AHI and ESS values & After treatment (T4) \\
\hline & Number of patients & $\%$ \\
$\mathrm{AHI}<5$ & 9 & 37.5 \\
$5 \leq \mathrm{AHI}<15$ & 10 & 41.67 \\
$15 \leq \mathrm{AHI}<30$ & 4 & 16.67 \\
$\mathrm{AHI} \geq 30$ & 1 & 4.17 \\
Decrease of the AHI $>50 \%$ & 21 & 87.5 \\
Diminution de l'IAH $>50 \%$ with an AHI $<10$ & 17 & 70.83 \\
ESS $<11$ & 14 & 58.33 \\
ESS $>11$ & 10 & 41.67 \\
\hline
\end{tabular}

end of the study, 21 patients saw their AHI decrease by $50 \%$ or more, proving the treatment is efficient. We also observed a normalization (i.e. an $\mathrm{AHI}<10$ ) in 17 patients $(70.83 \%$ ) who had worn a MAD for over 2 years. Previous studies had so far reported percentages of normalized patients between $43 \%$ and $61 \%$ [3]. Some studies did not find any significant difference of AHI reduction between CPAP and MAD treatment [4]. Some authors think the BMI might have an impact on the effectiveness of MADs, especially regarding the normalization of the AHI [5]. 20 of our patients (83.33\%) with a BMI $<30 \mathrm{~kg} / \mathrm{m}^{2}$ had an AHI $<10$ after treatment, while the other 4 patients $\left(16.67 \%\right.$ ) had a BMI $>30 \mathrm{~kg} / \mathrm{m}^{2}$, which confirmed our hypothesis. Furthermore, some authors demonstrated that MADs were much more effective than oral control devices against AHI and other physiological indicators of sleep apnea, although their effectiveness varied on more subjective parameters such as the ESS [6]. Our study revealed a significant decrease of ESS scores in our patients $(-4.5 ; P=0.001)$. Similar decreases in ESS scores were also reported in several studies [7]. Our patients had an average ESS score of 8.2 after more than 2 years of MAD treatment, a very close figure to results obtained with CPAP treatment [8]. This result suggests that MADs have beneficial results on daytime sleepiness of patients with OSAHS. Furthermore, we found no significant correlation between initial AHI and ESS values (correlation coefficient $=0.19 ; P=0.37$ ), which was also reported in another study [9]. Likewise, we found no significant correlation between ESS and AHI variations (correlation coefficient $=0.25 ; P=0.24$ ). Furthermore, we did not find any difference of ESS between patients with an AHI $<10$ and those with an AHI $>10(P=0.336)$. Finally, some authors reported that the design of the device had little impact on its clinical effectiveness, but that it could affect the treatment because of the patients' subjective preferences [10].

We observed slight but statistically significant changes of the maxilla position $(-0.287 ; P=0.039)$ and of the lower central incisor inclination $(+0.521 ; P=0.047)$ in patients under MAD

Table 2

Statistical description of cephalometric variables at T1 and T2 and of the average variation per year of these variables between T1 and T2

\begin{tabular}{|c|c|c|c|c|c|}
\hline \multirow[t]{2}{*}{ Variables } & & \multirow{2}{*}{$\frac{\mathrm{T} 1}{\mathrm{Ave}}$} & \multirow{2}{*}{$\begin{array}{l}\mathrm{T} 2 \\
\text { Average and standard deviation }\end{array}$} & \multicolumn{2}{|l|}{$\mathrm{T} 1-\mathrm{T} 2$} \\
\hline & & & & $\begin{array}{l}\text { Average difference per year (in } \\
\text { and } \mathrm{mm} \text { ) and standard deviation }\end{array}$ & $P$ \\
\hline \multirow[t]{2}{*}{ Maxillary central incisor inclination } & $\mathrm{I} / \mathrm{F}$ & $105.750 \pm 11.082$ & $104.250 \pm 10.637$ & $-0.290 \pm 0.218$ & 0.197 \\
\hline & D1 & $-0.375 \pm 3.597$ & $-0.565 \pm 3.836$ & $-0.033 \pm 0.152$ & 0.296 \\
\hline \multirow[t]{2}{*}{ Mandibular central incisor inclination } & i-Apog & $21.583 \pm 7.071$ & $23.625 \pm 7.890$ & $0.521 \pm 0.250$ & $0.047^{\mathrm{a}}$ \\
\hline & D2 & $0.333 \pm 4.114$ & $1.522 \pm 4.389$ & $0.250 \pm 0.139$ & 0.084 \\
\hline \multirow[t]{2}{*}{ Sagittal position of the maxilla } & A-NaPog & $6.458 \pm 4.559$ & $5.417 \pm 3.798$ & $-0.287 \pm 0.132$ & $0.039^{a}$ \\
\hline & D3 & $-1.542 \pm 5.469$ & $-2.609 \pm 5.150$ & $-0.170 \pm 0.185$ & 0.368 \\
\hline \multirow{2}{*}{ Sagittal position of the mandible } & NaPog-F & $87.375 \pm 3.831$ & $86.292 \pm 4.438$ & $-0.147 \pm 0.127$ & 0.258 \\
\hline & D4 & $-4.042 \pm 5.344$ & $-5.391 \pm 5.132$ & $-0.270 \pm 0.188$ & 0.164 \\
\hline
\end{tabular}

a Statistically significant result $(P>0.005)$. 
Table 4

Statistical description of patient distribution depending on the values of AHI and ESS values after treatment.

\begin{tabular}{|c|c|c|c|c|}
\hline Variables & Before treatment (T3) & After treatment (T4) & Difference T3- & \\
\hline & Average and standard deviation & Average and standard deviation & Average & $P$ \\
\hline AHI (number per hour) & $35.5 \pm 18.2$ & $9.3 \pm 9.4$ & $-26.1 \pm 14.5$ & $0.0001^{*}$ \\
\hline Number of obstructive apneas & $112.7 \pm 115.1$ & $25.8 \pm 39.2$ & $-95.0 \pm 99.8$ & $0.0147^{*}$ \\
\hline Number of hypopnea & $75.3 \pm 53.6$ & $52.5 \pm 49.0$ & $-25.8 \pm 62.5$ & 0.224 \\
\hline ESS & $12.4 \pm 4.6$ & $8.2 \pm 4.7$ & $-4.4 \pm 3.6$ & $0.001^{*}$ \\
\hline
\end{tabular}

"Stastically significant result $(P>0.005)$.

treatment for more than 2 years. However mandible position and upper central incisor inclination were not statistically significantly changed after long-term MAD treatments, as was the case in previous studies [11]. The most commonly admitted hypothesis is that if the mandible is pulled forward with a MAD, as with an orthopedic activator, reciprocal forces are exerted on soft tissues and on the mandible. In fact, the mandible tries to return to its normal position (backwards) during muscle relaxation and transmits a forward force on the lower central incisors and a backward force on the upper central incisors [12]. We observed that our patients' lower central incisors were significantly tilted forward. Several studies found similar results [12], while others did not report any changes [13]. We also observed a non-significant palatal tilt on the upper central incisors. This palatal tilt was reported as significant in other studies [14]. Furthermore, the various types of appliances we used did not alter the results. Some authors [15] showed that the side effects on teeth result mostly from mandibular protrusion, rather than from the design of the device. Other authors [16] suggested that the rigidity of the appliance and the extent of the patient's deep bite cause the apparition of dental side effects, not the device's design. These side effects may be prevented by a careful selection of patients, taking into account all contraindications; patients must have enough teeth and a healthy periodontium. Moreover, evaluations of the patients' compliance with MAD treatment would yield more reliable and objective results [15].

We also observed a significant backward movement of the maxilla, an observation made by other researchers [17]. However, some authors reported a significant forward movement of the maxilla $(P=0.023)$, which they did not consider clinically important [18]. Finally, other studies did not find any significant change in the position of the maxilla [12]. We did not observe any significant changes in mandible position, as was the case in some studies [12]; some authors reported a backward movement of the mandible [19] and others a forward movement [20].

Furthermore, several authors reported dental and skeletal changes correlated to the duration of MAD treatment and the frequency of use of the device. We made the same observations in our study [21]. The skeletal changes could be mainly linked to the vertical repositioning of the mandibular condyles (rather than a remodeling of the glenoid cavity or of the mandibular condyles). These skeletal changes occur soon after beginning the treatment, while dental changes occur all along the treatment, and thus may go unnoticed by some patients [22].

\section{Disclosure of interest}

The authors declare that they have no competing interest.

\section{Acknowledgments}

We thank Doctor François Lefèbvre of the Methodology and Biostatistics Department at the $\mathrm{CHU}$ de Strasbourg for his assistance in statistical data analysis.

\section{References}

[1] Delaire J, Schendel SA, Tulasne JF. An architectural and structural craniofacial analysis: a new lateral cephalometric analysis. Oral Surg Oral Med Oral Pathol 1981;52(3):226-38

[2] Ricketts RM. Nécessité de la céphalométrie en clinique orthodontique actuelle. Rev Orthop Dento Faciale 1975;9:293-308.

[3] Van Haesendonck G, Dieltjens M, Hamans E, Braem MJ, Vanderveken OM Treatment efficacy of a titratable oral appliance in obstructive sleep apnea patients: a prospective clinical trial. B-ENT 2016;12(1):1-8.

[4] White DP, Shafazand S. Mandibular advancement device vs. CPAP in the treatment of obstructive sleep apnea: are they equally effective in short term health outcomes? J Clin Sleep Med 2013;9(9):971-2.

[5] Sutherland K, Takaya H, Oian J, Petocz P, Ng AT, Cistulli PA. Oral appliance treatment response and polysomnographic phenotypes of obstructive sleep apnea. J Clin Sleep Med 2015;11(8):861-8.

[6] Marklund M, Carlberg B, Forsgren L, Olsson T, Stenlund H, Franklin KA. Oral appliance therapy in patients with daytime sleepiness and snoring or mild to moderate sleep apnea: a randomized clinical trial. JAMA Intern Med 2015;175(8):1278-85.

[7] Giannasi LC, Almeida FR, NacifSR, De OLiveira LV. Efficacy of an oral appliance for the treatment of obstructive sleep apnea. Int J Prosthodont 2013;26(4):334-9.

[8] Phillips CL, Grunstein RR, Darendeliler MA, Mihailidou AS, Srinivasan VK, Yee $\mathrm{BJ}$, et al. Health outcomes of continuous positive airway pressure versus oral appliance treatment for obstructive sleep apnea: a randomized controlled trial. Am J Respir Crit Care Med 2013;187(8):879-87.

[9] Walker-Engstrom ML, Ringqvist I, Vestling O, Wilhelmsson B, Tegelberg A. A prospective randomized study comparing two different degrees of mandibular advancement with a dental appliance in treatment of severe obstructive sleep apnea. Sleep Breath 2003;7(3):119-30.

[10] Bloch KE, Iseli A, Zhang JN, Xie X, Kaplan V, Stoeckli PW, et al. A randomized, controlled crossover trial of two oral appliances for sleep apnea treatment. Am J Respir Crit Care Med 2000;162(1):246-51.

[11] Doff MH, Finnema KJ, Hoekema A, Wijkstra PJ, De Bont LG, Stegenga B. Longterm oral appliance therapy in obstructive sleep apnea syndrome: a controlled study on dental side effects. Clin Oral Investing 2013;17(2):475-82.

[12] Wang X, Gong X, Yu Z, Gao X, Zhao Y. Follow-up study of dental and skeletal changes in patients with obstructive sleep apnea and hypopnea syndrome with long-term treatment with the Silensor appliance. Am J Orthod Dentofacial Ortho 2015;147(5):559-65.

[13] Fritsch KM, ISeli A, Russi EW, Bloch KE. Side effects of mandibular advancement devices for sleep apnea treatment. Am J Respir Crit Care Med $2001 ; 164(5): 813-8$

[14] Zhu Y, Long H, Jian F, Lin J, Zhu J, Gao M, Lai W. The effectiveness of oral appliances for obstructive sleep apnea syndrome: a meta-analysis. J Dent 2015;43(12):1394-402.

[15] Rose EC, Staats R, Virchow CJR, Jonas IE. Occlusal and skeletal effects of an oral appliance in the treatment of obstructive sleep apnea. Chest 2002;122(3):871-7.

[16] Marklund M, Persson M, Franklin K Orthodontic side-effects of mandibula advancement devices during treatment of snoring and sleep apnoea. Eur J Orthod 2001;23(2):135-44.

[17] Ghazal A, Jonas IE, Rose EC. Dental side effects of mandibular advancement appliances: a 2-year follow-up. J Orofac Orthop 2008;69(6):437-47.

[18] Ringqvist M, Walker-Engstrom ML, Tegelberg A, Ringqvist I. Dental and skeletal changes after 4 years of obstructive sleep apnea treatment with a mandibular advancement device: a prospective, randomized study. Am J Orthod Dentofacial Orthop 2003;124(1):53-60.

[19] Gong X, Zhao Y, Gao XM, Zeng XL. A follow-up study on the dental and skeletal changes of patients with obstructive sleep apnea and hypopnea syndrome treating by oral appliance. Chin J Orthod 2009;16:130-4.

[20] Bondemark L, Lindman R. Craniomandibular status and function in patients with habitual snoring and obstructive sleep apnoea after nocturnal treatment with a mandibular advancement splint: A 2-year follow-up. Eur J Orthod 2000;22(1):53-60.

[21] Marklund M. Predictors of long-term orthodontic side effects from mandibular advancement devices in patients with snoring and obstructive sleep apnea. Am J Orthod Dentofacial Orthop 2006;129(2):214-21.

[22] Hoekema A, Stegenga B, De Bont LG. Efficacy and co-morbidity of oral appliances in the treatment of obstructive sleep apnea-hypopnea: a systematic review. Crit Rev Oral Biol Med 2004;15(3):137-55. 